\title{
JPEB
}

\section{OPTIMALISASI KUALITAS PRODUK LAYANAN PURNA JUAL CHEVROLET SUMBER ANDALAN JOGJA DENGAN PENDEKATAN QFD}

\author{
Handy Nur Cahya*
}

Program Studi Manajemen, Fakultas Ekonomi dan Bisnis, Universitas Dian Nuswantoro

\author{
Jalan Nakula I No. 5-11 Semarang, Indonesia \\ *Corresponding Email : handy.nur@dsn.dinus.ac.id
}

Diterima: April 2018; Direvisi: Juli 2018; Dipublikasikan: September 2018

\begin{abstract}
Stagnant sales in Chevrolet vehicle are indicated due to the quality of the after sales service product that is not optimal yet. Poor sales performance forced Chevrolet to do efficiency by closing some of its dealers. As a result, Chevrolet Sumber Andalan Jogja became the sole dealer in the Central Java region. The purpose of this study is to identify consumer needs, identify how the company can meet consumer needs (technical response), and determine the priority level of each. The research was conducted in descriptive research by observing the Chevrolet Sumber Andalan Jogja, distributing questionnaires, processing data, and analyzing using QFD. The results of the study show that consumers' needs for Chevrolet's after-sales service products cover 6 variables, namely reliability, price, speed, stock, facilities, and service. The company's technical response is based on the order of priorities including complementing service and repair tools, adding more service terminals, extending operating hours, providing training to staff and technicians, and adding additional employees.
\end{abstract}

Keywords : Quality Function Deployment; Operations; Product Improvement

\begin{abstract}
ABSTRAK
Penjualan yang stagnan pada produk Chevrolet terindikasi disebabkan oleh kualitas produk layanan purna jual yang belum optimal. Kinerja penjualan yang kurang baik memaksa Chevrolet melakukan efisiensi dengan menutup sebagian dealernya. Akibatnya Chevrolet Sumber Andalan Jogja menjadi dealer tunggal di kawasan pulau Jawa bagian Tengah. Tujuan dari penelitian ini adalah mengidentifikasi kebutuhan konsumen, mengidentifikasi bagaimana perusahaan dapat memenuhi kebutuhan konsumen (respon teknis), dan menentukan tingkat prioritas masing masing. Penelitian dilakukan secara descriptive research dengan melakukan observasi di Chevrolet Sumber Andalan Jogja, melakukan penyebaran kuesioner, mengolah data dan menganalisa menggunakan QFD. Hasil penelitian menunjukkan kebutuhan konsumen akan produk layanan purna jual Chevrolet secara prioritas meliputi 6 variabel, yaitu keandalan, harga, kecepatan, stok, sarana, dan pelayanan. Respon teknis perusahaan berdasarkan urutan prioritas meliputi: melengkapi alat servis dan perbaikan, menambah terminal servis, memperpanjang jam operasional, memberi pelatihan kepada staf dan teknisi, dan menambah pegawai.
\end{abstract}

Kata Kunci : Quality Function Deployment; Operasional; Peningkatan Kualitas 


\section{PENDAHULUAN}

Chevrolet merupakan pemain otomotif besar di dunia yang berdiri sejak tahun 1908 . Chevrolet berkantor pusat di DetroitAmerika Serikat. Penjualan raksasa otomotif ini mencapai 9,1 juta unit pada tahun 2005 dan menguasai market share mobil secara global sebesar 14,5\% (Jagodzinsky et. all, 2006). Di Indonesia, Chevrolet sudah menjejakkan dirinya mulai tahun 1920. Pabrikan mobil bermerek Chevrolet menjual banyak lini produk di pasar indonesia, mulai dari SUV, Truck, Sedan, MPV, dan hatchback, tentunya dengan kualitas produk terbaik khas kendaraan buatan Amerika (ChevroletID, 2000).

Meskipun masyarakat Indonesia paham akan kualitas produk dari Chevrolet, tapi nama besar Chevrolet tidak serta merta mampu menarik perhatian secara masif. Produk mobil Jepang tetaplah pemenang bagi kebanyakan masyarakat Indonesia (Salim \& Dharmayanti, 2014). Kebanyakan masyarakat Indonesia melakukan pembelian mobil dengan mengedepankan brand image dan perceived quality secara turun menurun, apa yang sudah digunakan orang tua akan ikut digunakan oleh anak mereka. Masyarakat enggan mengambil resiko terhadap sesuatu yang belum lazim dipakai kebanyakan. Hal ini menyebabkan penetrasi pasar mobil Chevrolet sulit membendung geliat mobil asal Jepang.

Namun begitu Chevrolet dengan gigihnya terus mencoba bertumbuh di pasar Indonesia dengan munculnya Chevrolet SPIN, salah satu produk MPV dan Chevrolet Trax, salah satu produk Crossover, mampu meningkatkan penjualan sebesar 34,5\% year on year (y.o.y) (GMPressroom, 2018). Peningkatan penjualan sepanjang tahun 2018 padaproduk Chevrolet di Indonesia ternyata tidak serta merta membawa keuntungan sepenuhnya (Gaikindo, 2018). Di dalam manajemen chevrolet indonesia, perusahaan harus berbenah dan melakukan efisiensi, hingga puncaknya pada agustus 2017 banyak dealer penjualan dan layanan purna jual Chevrolet ditutup (Sag, 2018). Penutupan ini juga berimbas hingga ke Jawa Tengah dan Daerah Istimewa Yogyakarta (DIY), yang merupakan satu kawasan marketing yang sama, yakni pulau Jawa bagian tengah.

Dikawasan penjualan pulau Jawa bagian tengah, awalnya terdapat 4 dealer dan layanan servis purnajual chevrolet, yaitu di Semarang, Magelang, Solo, dan Yogyakarta. Atas alasan efisiensi kemudian General Motor Indonesia selaku induk dari dealer Chevrolet memutuskan untuk hanya menyisakan satu dealer di kawasan pulau Jawa bagian tengah, yaitu dealer Yogyakarta. Dealer Chevrolet Yogyakarta memiliki nama usaha Chevrolet Sumber Andalan Jogja, beralamat di Jalan Magelang KM. 7.2 Sendangadi Mlati, Sleman, Yogyakarta. Dealer ini kemudian menjadi dealer satu satunya yang menangani baik penjualan maupun layanan purna jual resmi Chevrolet di pulau jawa bagian tengah, mengcoverlayanan bagi dealer Chevrolet wilayah Semarang, Magelang, dan Solo.

Setelah penutupan 3 dealer sebagai usaha efisiensi kegiatan operasional, Chevrolet Sumber Andalan Jogja harus menelan kekecewaan ternyata banyak konsumennya yang berasal dari luar kota Yogyakarta enggan jauh jauh datang ke jogja hanya untuk sekedar melakukan servis, melainkan konsumen lebih memilih menggunakan jasa servis di bengkel bengkel spesialis yang ada di kota masing masing. Hal ini diindikasikan karena kualitas layanan purna jual bengkel chevrolet seperti harga produk layanan purna jual, kualitas tempat tunggu, dan waktu antrian yang terlalu lama berada dibawah kualitas bengkel mobil resmi bermerek asal Jepang seperti Toyota, Daihatsu, dan Mazda. Bengkal yang hanya ada sedikit bahkan hanya ada satu di Yogyakarta ditengarai sebagai penyebabnya (Carmudi, 2017).

Kualitas produk layanan purna jual ini membuat masyarakat enggan menggunakan produk dari chevrolet, meskipun secara kualitas produk mobil, build quality Chevrolet diatas rata rata kualitas produk dikelasnya (GM-Media, 2018). Hal ini menjadi permasalahan utama bagi Chevrolet Sumber Andalan Jogja saat ini, bagaimana meyakinkan konsumen atas produk layanan purna jual Chevrolet. Tujuannya adalah agar dealer satu satunya yang ada di Jawa bagian tengah ini mampu memberikan peningkatan penjualan produk layanan purna jual. 
Maka, peneliti merasa tepat menggunakan Quality Function Deployment (QFD) sebagai alat untuk menemukan solusi atas permasalahan yang dihadapi Chevrolet Sumber Andalan Jogja. Penggunaan QFD memungkinkan untuk menemukan faktor apa saja yang dibutuhkan konsumen, bagaimana cara perusahaan dapat memenuhi kebutuhan konsumen tersebut, lengkap beserta prioritas kebutuhannya.

Hal ini sejalan dengan tujuan penelitian ini, yaitu mengidentifikasi faktor faktor apa saja yang merupakan kebutuhan konsumen, menganalisis bagaimana faktor kebutuhan konsumen dapat dipenuhi oleh perusahaan (respon teknis), dan menentukan prioritas langkah pemenuhan kebutuhan tersebut.

\section{TINJAUAN PUSTAKA}

\section{Quality Function Deployment (QFD)}

QFD merupakan metode yang digunakan untuk mengidentifikasi apa sja kebutuhan konsumen dan dikonversi menjadi apa yang harus dilakukan perusahaan untuk memenuhi kebutuhan konsumen tersebut (Heizer \& Render, 2010). Dalam menggunakan QFD diperlukan adanya alat bantu, yaitu House of Quality (rumah kualitas). Rumah kualitas merupakan bagan berbentuk rumah yang dapat digunakan untuk mempermudah pengambilan keputusan dalam dilakukannya proses QFD. House of Quality (HoQ) terdiri dari 6 bagian, yakni ruang kiri, ruang kanan, ruang atas, ruang tengah, ruang bawah, dan ruang atap. Masing-masing ruangan yang ada memiliki fungsi kegunaan berbeda beda ketika digunakan dalam penelitian. Adapun bagian dan fungsi dari HoQ adalah seperti tersaji pada Gambar 1 berikut:

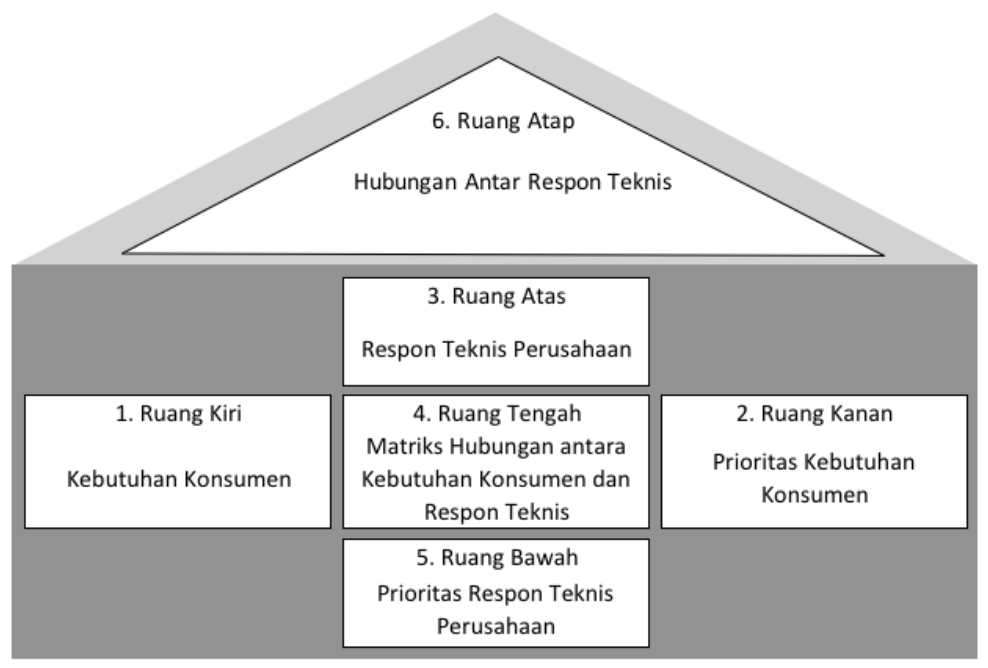

Gambar 1. House of Quality (HoQ)/Rumah Kualitas

Tahap penyusunan HoQ diawali dengan melakukan survei awal (prasurvey) kepada segenap konsumen. Prasurvei ditujukan untuk memperoleh gambaran mengenai apa saja hal hal yang dapat dipertanyakan kepada sejumlah konsumen/responden yang lebih besar pada saat survei utama dilaksanakan. Data hasil prasurvei dikelompokkan menggunakan diagram affinitas sesuai tingkat kemiripan kategori.

Setelah diagram affinitas terbentuk, data dari diagram affinitas digunakan untuk menyusun diagram pohon. Butir atribut pada diagram pohon digunakan sebagai bahan pertanyaan pada kuesioner penelitian. Kemudian, diagram pohon juga merupakan bahan untuk mengisi HoQ pada bagian ruang kiri. Setelah ruang kiri selesai, dilanjutkan dengan menghitung data hasil survey untuk menentukan prioritas kebutuhan konsumen yang dapat dilihat di ruang kanan HoQ. Tahap selanjutnya dilanjutkan dengan menentukan respon teknis perusahaan untuk memenuhi berbagai kebutuhan konsumen. Hal ini tercermin dalam ruang 
atas HoQ. Respon teknis diperoleh dari data hasil FGQ dengan manajemen internal perusahaan yang diobservasi.

Tahap selanjutnya adalah menghitung tingkat keterkaitan antara masing masing respon teknis yang ada dengan kebutuhan konsumen yang ada. Tahap ini dilakukan di ruang tengah HoQ. Penilaian dilakukan secara FGD dengan manajemen perusahaan untuk dapat mengetahui tingkat pengaruh masing masing atribut. Selanjutnya untuk menghitung prioritas respon teknis dapat dilihat pada ruang bawah. Ruang bawah berisi perhitungan dari tingkat kepentingan di ruang tengah. Nilai dengan jumlah skor tertinggi pada ruang bawah akan menjadi prioritas respon teknis yang harus didahulukan untuk dilaksanakan.

\section{Kualitas}

Kualitas merupakan karakteristik yang melekat dalam sebuah produk, baik produk berupa barang maupun produk berupa jasa. Berbicara mengenai kualitas berarti berbicara sesuatu yang tidak mutlak, melainkan relatif. Produk dikatakan berkualitas ketika dapat memenuhi harapan/keinginan konsumen, paling tidak selevel/lebih dengan harapan konsumen (Brown, Bessant, \& Lamming, 2013); (Parasuraman, Zeithaml, \& Berry, 1985).

Produk merupakan segala yang ditawarkan kepada calon konsumen, agar ketika dijual menghasilkan keuntungan bagi penjual (Buchory \& Saladin, 2010). Ketika berbicara mengenai produk, pengembangan produk itu sendiri tidak hanya akan berfokus pada wijud fisiknya saja, melainkan juga harus mempertimbangkan mengenai komponen inti, komponen pembungkus, dan komponen pendukung (Hisrich \& Peter, 1991, dalam Sulistriani, 2002).

\section{METODE PENELITIAN}

Penelitian ini merupakan descriptive research. Data diperoleh dengan cara dengan melakukan observasi langsung pada Chevrolet Sumber Andalan Jogja. Kemudian melakukan prasurvey. Setelahnya survey besar dilaksanakan menggunakan kuesioner kepada konsumen yang sedang melakukan servis untuk mengetahui faktor-faktor kebutuhan konsumen. Pengisian survey disertai berdiskusi dengan konsumen agar diketahui alasan yang lebih mendalam atas argumen dan jawaban konsumen pada kuesioner.

Selanjutnya FGD dengan manajemen dilakukan untuk memperoleh informasi mengenai langkah yang bisa dilakukan untuk memenuhi kebutuhan konsumen. Pada tahap selanjutnya analisa data dilakukan dengan menggunakan QFD yang melibatkan HoQ untuk menentukan prioritas kebutuhan konsumen beserta prioritas respon teknis.

Konsumen yang dilibatkan adalah 8 konsumen pada prasurvey, dan32 konsumen pada survey utama. FGD dilakukan untuk memperoleh respon teknis melibatkan manajemen perusahaan yaitu manajer operasional, manajer keuangan, dan kepala cabang Chevrolet Sumber Andalan Jogja. Data data yang diperoleh diuji tingkat reliabilitasnya menggunakan SPSS 22 untuk memastikan data yang ada sudah reliabel $(>0,6)$. Hasil uji reliabilitas pada variabel "keandalan" yang terdiri dari atribut kualitas pemeliharaan, kualitaspart, rentang garansi, dan rentang pakai, menghasilkan skor 0,816. Variabel "kecepatan" terdiri dari atribut kecepatan servis, kecepatan diagnosa, dan kecepatan klaim menghasilkan skor 0,632. Variabel "stok" yang terdiri dari atribut ketersediaan sparepart dan sistem inden menghasilkan skor 0,786 . Untuk variabel "harga" dengan skor 0,797, variabel "pelayanan" dengan skor 0,766, dan "variabel" sarana dengan skor 0,771 .

\section{HASIL DAN PEMBAHASAN}

Tahap awal penelitian dilakukan dengan melakukan wawancara awal kepada 8 konsumen servis di Chevrolet Sumber Andalan Jogja untuk memperoleh data awal pra survei. Hasil temuan pada wawancara pra survei ini menghasilkan 28 suara konsumen (voice of customer), tersaji pada gambar 2: 
Handy Nur Cahya : Optimalisasi Kualitas Produk Layanan Purna Jual Chevrolet Sumber Andalan Jogja dengan Pendekatan QFD

\begin{tabular}{|cc|}
\hline Harga bersaing & Klaim garansi lama \\
Layanan service cepan & Pelayanan lama \\
Antrian tidak Panjang & Layanan garansi kurang bagus \\
Hasil servis bagus, Awet, & service selalu penuh, antri lama \\
Mendeteksi masalah kendaraan cepat & Konsumsi seadanya \\
Diskon service rutin & Ruang tunggu jauh dibawah standar \\
Sparepart selalu siap & Antrian dipenuhi mobil merek lain \\
Pembayaran transfer tersedia & Inden sprarepart lama \\
Ruang tunggu dibersihkan & Onderdil dan suku cadang mahal \\
Ruang tunggu rokok dan tidak merokok tidak ada sekat & CS ramah penjelasan mudah dimengerti \\
Layanan ramah & Mekanik handal \\
Tempat tunggu luas & Hanya ada satu tempat servisnya \\
Ruang tunggu panas & Alat alat servis cangging \\
Ruang tunggu modern & Ada bengkel body repair berkelas
\end{tabular}

Gambar 2. Suara Konsumen

Suara konsumen dikelompokan menggunakan diagram affinitas, yang kemudian hasilnya digunakan untukmeyusunan diagram pohon. Informasi mengenai pengelompokan suara konsumen menggunakan diagram affinitas tersaji dalam Gambar 3:

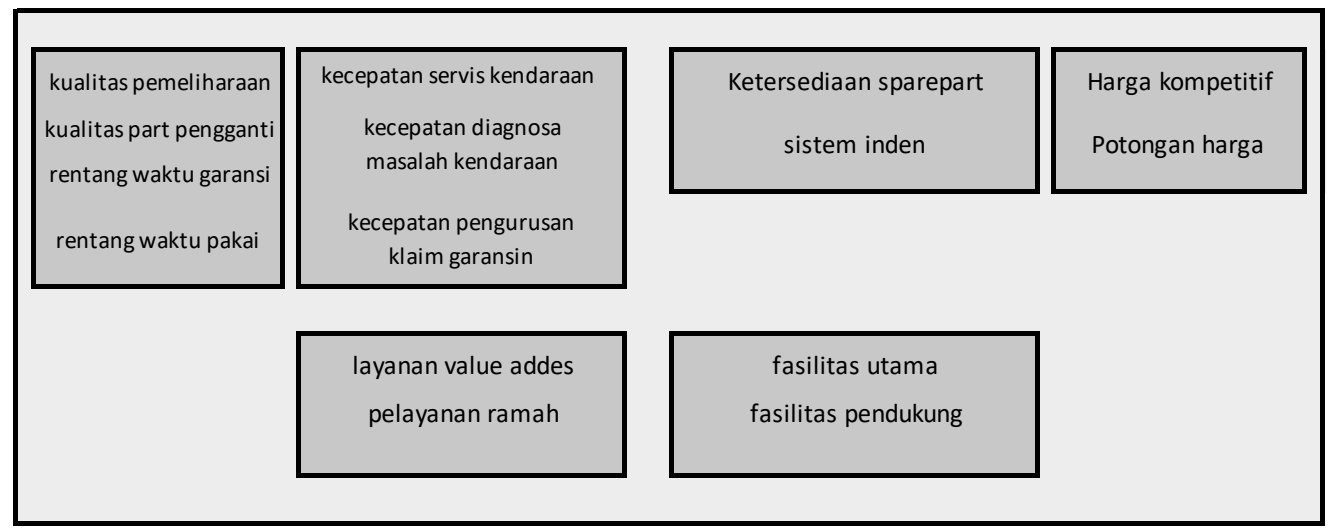

\section{Gambar 3. Diagram Affinitas}

Butir dalam diagram affinitas kemudian disusun pada diagram pohon sebagai dasar pertanyaan dalam kuesioner untuk melakukan surveiutama. Pengelompokan tersebut dapat dilihat pada Gambar 4: 


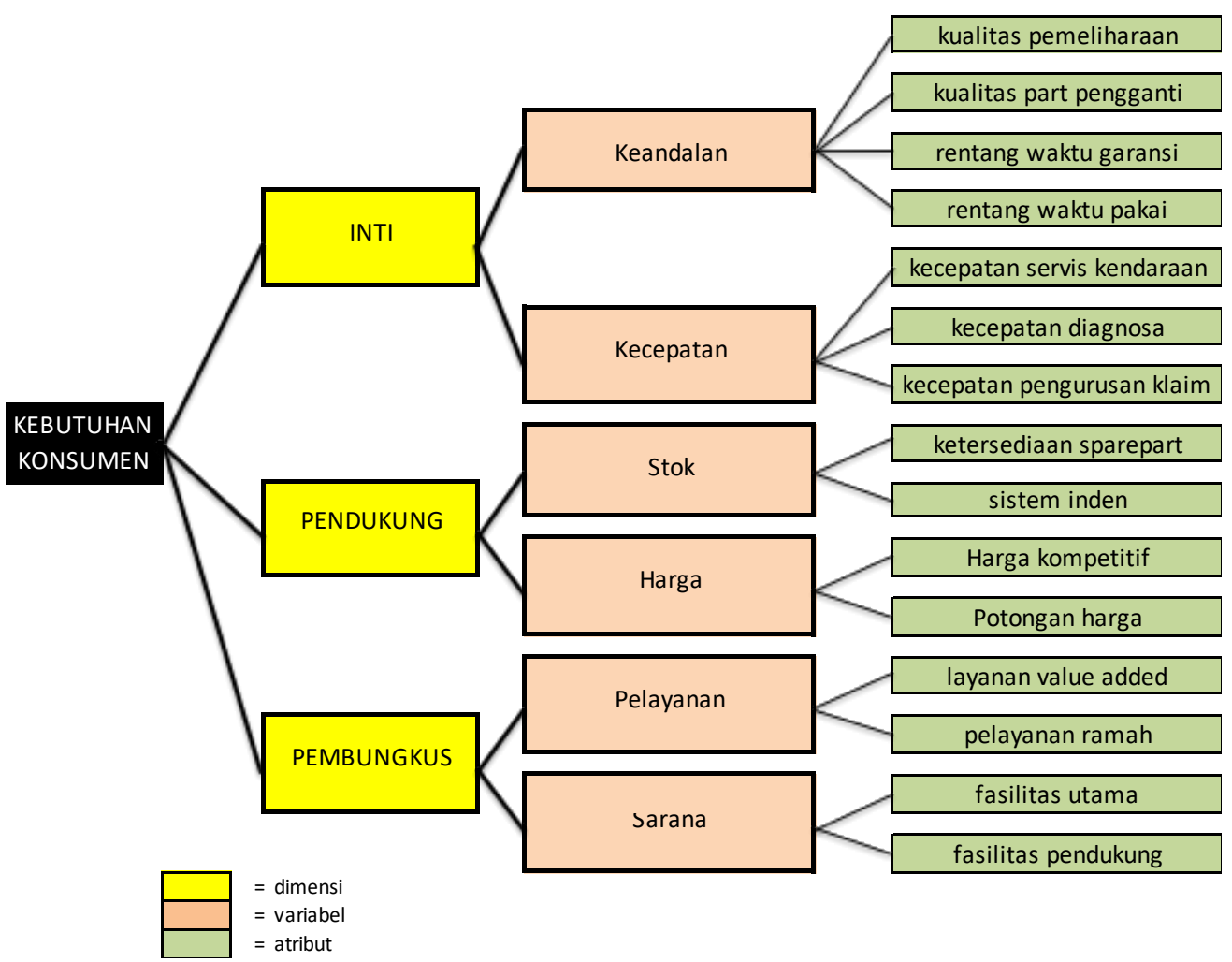

Gambar 4. Diagram Pohon

Komponen dimensi dan komponen variabelpada diagram pohon merupakan bagian yang digunakan untuk menyusun ruang kiri HoQ. Di Ruang kiri HoQ, seperti tersaji pada Gambar 5, diperoleh data mengenai kebutuhan konsumen dalam 6 variabel. Variabel tersebut adalah keandalan, kecepatan, stok, harga, pelayanan, dan sarana. Variabel - variabel yang teridentifikasi menggambarkan aspek apa saja yang menjadi kebutuhan konsumen akan produk layanan purna jual perusahaan. Perhitungan prioritas kebutuhan konsumen selanjutnya dilakukan berdasarkan data tabulasi kuesioner. Hasil tabulasi data akan digunakan sebagai dasar menghitung prioritas kebutuhan konsumen di ruang kanan HoQ.

Ditunjukkan pada ruang kanan Gambar 5 mengenai House of Quality Secara Utuh, dimensi intipada variabel Keandalan dengan skor 3,914menjadi peringkat pertama. Hal ini menunjukkan bahwa variabel Keandalan adalah hal yang paling diinginkan konsumen, Konsumen menginginkan adanya kualitas pemeliharaan/servis yang baik. Artinya, konsumen berharap sparepart yang digunakan adalah part original yang memiliki masa pakai lama. Sehingga dapat membuat konsumen tidak harus terlalu sering melakukan perbaikan kendaraan. Dalam variabel kecepatan, konsumen menginginkan waktu yang sesingkat mungkin dalam mendiagnosa kerusakan pada kendaraan mereka, namun tetap menghasilkan analisa yang akurat. Untuk atribut klaim garansi, konsumen juga menginginkan adanya perbaikan mekanisme alur klaim, sehingga proses klaim garansi yang diperlukan tidak terlalu lama. 


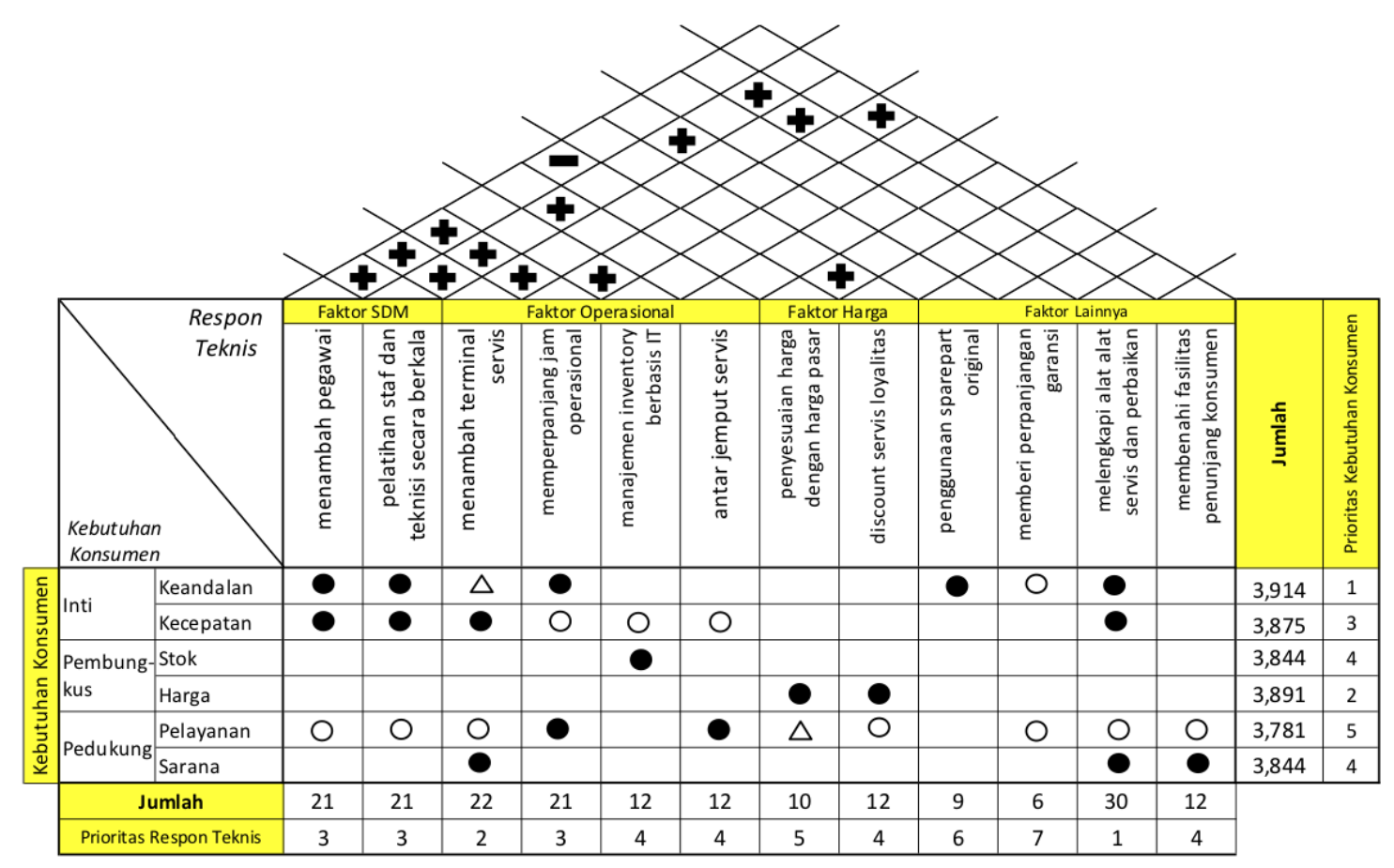

Gambar 5. House of Quality secara utuh

Variabel Harga dengan skor 3,891 menduduki peringkat kedua. Peringkat ini menunjukkan bahwa konsumen menginginkan adanya penurunan harga pada produk layanan purna jual Chevrolet. Harga sparepart dan oli pelumas yang ada di bengkel Chevrolet Sumber Andalan Jogja maupun dealer chevrolet lainnya dinilai terlalu mahal oleh konsumen. Untuk produk pelumas dengan merek dan unit yang sama, harga jual dealer dibandingkan dengan harga di pasaran memiliki selisih harga hingga 100rb per liter. Sebagai contoh, oli standar yang biasa digunakan pada kendaraan Chevrolet tipe bensin adalah Oli Q8 Special G Long Life D1 SAE 5W-30 API SN GF-5 Dexos 1, harga di pasaran berkisar di Rp145.000 per liter (ATPMOIL, Q8 special G long life d1 sae 5w30, 2018), dan oli untuk tipe diesel Oli Q8 Formula Excel SAE 5W40 Diesel High Performance Synthetic Oil 1L juga berkisar di Rp145.000 per liter (ATPMOIL, Q8 Formula Excel 5w40 Diesel, 2018). Namun, harga jual untuk kedua produk yang sama tersebut di dealer resmi Chevrolet berdasarkan hasil observasi dibanderol dengan harga pada kisaran Rp275.000 per liter.

Perbedaan harga yang cukup jauh menyebabkan konsumen Chevrolet enggan melakukan penggantian oli di bengkel resmi Chevrolet Sumber Andalan Jogja setelah masa garansi kendaraan berakhir. Implikasinya adalah pendapatan Chevrolet dari sisi pemasukan produk layanan purna jual tidak optimal. Konsumen lebih memilih melakukan penggantian oli pelumas di bengkel spesialis Chevrolet maupun dengan membeli oli secara online untuk kemudian melakukan penggantian secara mandiri dikarenakan selisih harga yang cukup banyak. Pada variabel Harga, ditemukan pula bahwa konsumen menginginkan adanya potongan harga tarif jasa servis kendaraan yang telah habis masa garansi.

Variabel kecepatan dengan skor 3,875 menjadi faktor terpenting ketiga. Hal ini menunjukkan konsumen menginginkan adanya kecepatan dalam pengerjaan servis rutin kendaraan, kecepatan dalam pengurusan klaim garansi, serta kecepatan dalam perbaikan kerusakan. Terdapat pula keinginan konsumen dalam hal adanya value added service. Konsumen menginginkan adanya layanan antar jemput servis mobil khususnya bagi konsumen dalam kota Yogyakarta. Layanan antar jemput mobil diinginkan karena kerap terjadinya antrian servis yang sangat panjang pada akhir pekan.

Konsumen juga mengharapkan adanya perbaikan dalam faktor sarana. Karena 
Chevrolet Sumber Andalan Jogja menjadi satu satunya tulang punggung layanan purna jual di pulau jawa bagian tengah, maka harapan konsumen adalah adanya lebih banyak fasilitas terminal servis, sehingga dalam satu waktu bisa mengerjakan tidak hanya 5 kendaraan. Tujuannya agar pengerjaan servis dan antrian tidak sepanjang yang ada saat ini pada akhir pekan. Ketersediaan sparepart menjadi masalah tersendiri bagi kendaraan merek Chevrolet. Tidak jarang kebutuhan part pengganti sering kosong, akibatnya kendaraan yang perlu perbaikan tidak dapat ditangani dengan segera. Konsumen perlu datang berkali kali untuk memperbaiki kendaraan paling tidak 2 kali hingga kendaraan mereka selesai diperbaiki. Hal ini terlihat dari banyaknya kendaraan yang bermalam di ruang servis bengkel. Kendaraan dari berbagai jenis kelas mengantri untuk diperbaiki karena sparepart yang masih inden dari kantor pusat Chevrolet Jakarta. Tentunya tersebut menjadi sangat tidak efisien bagi konsumen karena kendaraan mereka tidak dapat dioperasionalkan dalam jangka waktu tertentu sebagaimana mestinya.

Padi variabel Sarana, atribut fasilitas pendukung seperti kenyamanan ruang tunggu juga perlu adanya perbaikan. Konsumen merasakan kurang nyaman dengan fasilitas ruang tunggu yang ada. Ruang antara smooking room dan non smooking room tidak ada sekat pembatas, sehingga asap bercampur di kedua ruangan. Fasilitas pendingin ruangan juga kerap tidak dioperasikan. Akibatnya hawa panas dirasakan konsumen dan menyebabkan rasa tidak nyaman ketika harus menunggu waktu servis yang cukup lama. Ketersediaan makanan dan minuman juga sudah ada, tapi masih terkesan sekedarnya, terkadang stok air minum habis, dan sisa makanan dari konsumen dari hari sebelumnya masih berada di meja ruang tunggu. Hal seperti ini perlu adanya perbaikan agar kenyamanan konsumen bisa meningkat.

Ruang atas HoQ menunjukkan respon teknis pemenuhan kebutuhan konsumen. Respon teknis yang dapat dilakukan oleh manajemen Chevrolet Sumber Baru Jogja adalah menambah pegawai, pelatihan staff dan teknisi secara berkala, menambah terminal servis, memperpanjang jam operasional jika memungkinkan (kondisional), menggunakan manajemen inventory berbasis IT, layanan antar jemput kendaraan servis, penyesuaian harga, diskon servis loyalitas, penggunaan sparepart original, fasilitas perpanjangan garansi, melengkapi alat alat servis dan perbaikan, serta membenahi fasilitas penunjang konsumen.

Seperti yang ditunjukkan pada Ruang Bawah HoQ di Gambar 5 mengenai House of Quality secara utuh, respon teknis yang memperoleh peringkat 1 dengan skor 30 yaitu respon teknis mengenai melengkapi alat alat servis dan perbaikan. Hal ini menunjukkan bahwa melengkapi alat servis dan perbaikan menjadi faktor paling utama yang harus dilakukan oleh manajemen berdasarkan hasil kalkulasi prioritas HoQ. Menambah terminal servis berada di prioritas kedua dengan skor 22. Hal ini diperlukan perlu untuk mengakomodasi jumlah antrian servis yang ada. Diharapkan dalam satu waktu bengkel servis bisa mengerjakan perbaikan/perawatan mobil dalam jumlah yang banyak sekaligus.

Pada peringkat 3 dengan skor 21, terdapat tiga hal sekaligus yaitu melakukan perpanjangan jam operasional, memberikan pelatihan kepada staf dan teknisi secara berkala, dan opsi penambahan pegawai. Melakukan tambahan jam operasional bengkel perlu dilakukan khususnya pada waktu penjelang libur panjang. Jam kerja bengkel bisa ditambah karena menjelang hari libur panjang atau hari besar keagamaan tren melakukan servis kendaran selalu meningkat (Purnama, 2018). Memberikan pelatihan staf dan teknisi secara berkala dilakukan guna meningkatkan kapabilitas pekerja, sehingga dalam melayani konsumen dapat memberikan impresi yang baik dan kualitas kerja yang memenuhi standar. Opsi menambah pegawai perlu dipertimbangkan karena tren konsumen dari waktu ke waktu semakin menanjak, sehingga penambahan pegawai khususnya mekanik sangat diperlukan untuk dapat menyelesaikan antrian servis dengan lebih cepat.

Salah satu peringkat 4 dengan skor 12 adalah penggunaan inventory manajemen berbasis IT yang juga perlu dilakukan untuk memastikan ketersediaan stok yang sering 
kosong. Stok kosong ini terjadi karena manajemen inventori masih dilakukan secara manual, sehingga staf sering tidak siap sedia dalam mengupdate ketersediaan stok sparepart dan melakukan pemesanan. Dengan menggunakan teknologi manajemen inventory, software yang ada dapat secara otomatis mendata inventory mana yang akan segera habis dan dapat melakukan pemesanan secara otomatis ke kantor pusat.

Untuk prioritas respon teknis lain yang memiliki skor kecil, sebaiknya tetap diperhatikan oleh manajemen, walaupun sifatnya tidak masuk dalam prioritas. Seperti opsi penyesuaian harga misalnya, dengan skor 10 berada pada peringkat 5 .

\section{SIMPULAN}

Berdasarkan pembahasan yang telah dilakukan, dapat teridentifikasi faktor hal hal apa saja yang menjadi kebutuhan konsumen dan juga dapat terindentifikasinya respon teknis perusahaan dalam rangka memenuhi kebutuhan konsumen. Kebutuhan konsumen (voice of customer) berdasarkan urutan prioritasnya meliputi (1) variabel keandalan, (2) variabel harga, (3) variabel kecepatan, (4) variabel stok dan variabel sarana, dan (5) variabel pelayanan. Variabel "keandalan" terdiri dari atribut kualitas pemeliharaan, kualitas part pengganti, rentang waktu garansi, dan rentang waktu pakai. Variabel "harga" terdiri dari atribut harga yang kompetitif dan adanya potongan harga. Variabel "kecepatan" terdiri dari kecepatan servis kendaraan, kecepatan mendiagnosa kendaraan, dan kecepatan pengurusan klaim.

Respon teknis perusahaan (technical response) berdasarkan urutan prioritas utamanya meliputi (1) melengkapi alat servis dan perbaikan, (2) menambah terminal servis, (3) memperpanjang jam operasional, memberikan pelatihan kepada staf dan teknisi secara berkala, serta diadakan penambahan pegawai.

\section{DAFTAR PUSTAKA}

Asadabadi, M. R. 2016. A Markovian-QFD Approach In Addressing The Changing Priorities Of The Customer Needs. International Journal of Quality \& Reliability Management.

33 (8): 1062-1075.

ATPMOIL. 2018. Q8 Formula Excel 5w40 Diesel. Retrieved from Tokopedia: https://www.tokopedia.com/atpmoil/oli-q8-formula-excel-sae-5w40-diesel-highperformance-synthetic-oil-11?

ATPMOIL. 2018. Q8 special $G$ long life $d 1$ sae 5w30. Retrieved from Tokopedia: https://www.tokopedia.com/atpmoil/oli-q8-special-g-long-life-d1-sae-5w-30-api-sngf-5-dexos-1-kuwait-11-1?

Brown, S., Bessant, J., \& Lamming, R. 2013. Strategic Operations Management, 3rd ed. New York: Routledge.

Buchory, H., \& Saladin, D. (2010). Manajemen Pemasaran: Teori, Aplikasi dan Tanya Jawab. Bandung: Linda Karya.

Carmudi. 2017. Pabrikan dengan Aftersales terbaik. Retrieved from Carmudi: https://www.carmudi.co.id/advice/anjuran-mobil/pabrikan-indonesia-aftersalesterbaik/

ChevroletID. 2000. history and heritage of chevrolet. Retrieved from Chevrolet Indonesia: https://www.chevrolet.co.id/culture/article/history-and-heritage.html

Day, R. G. 1993. Quality Function Deployment. Winconsin: ASQC Quality Press.

Fatimah, R. P., Jemain, A. A., Anuar, K., \& Nasir, S. M. 2005. Marriage Deployment In Determining Priority Needs Using Quality Function Deployment (Qfd): A Service Organization's Perspective Approach. Penang: ICOQSIA.

Gaikindo. 2018. Wholesale Jan-Dec 2018. Retrieved from Gaikindo: https://files.gaikindo.or.id/process.php?do=download\&id=206 
GM-Pressroom. 2018. GM Mencatat Pertumbuhan Penjualan 34,6 Persen Di Indonesia. Retrieved from General Motor Pressroom: https://media.gm.com/media/id/id/chevrolet/news.detail.html/content/Pages/news/id/i d/2018/feb/0202-results.html

GM-Media. 2018. GM Media. Retrieved from GM: https://media.gm.com/media/th/en/chevrolet/home.detail.html/content/Pages/news/th/ en/2018/june/0605_ChevDurable.html

Heizer, J., \& Render, B. 2010. Operations Management. New Jersey: Prentice Hall.

Jagodzinsky, R., Kelemen, M., Stracke, S., \& Neumann, L. (2006). EWCs in the new Member States. Dublin: European Foundation for the Improvement of Living and Working Conditions.

Kompas. 2012. Sejarah Chevrolet di Indonesia. Retrieved from Kompas : https://ekonomi.kompas.com/read/2012/07/11/11372133/Sejarah.Mobil.dan.Kisah.Ke hadiran.Mobil.di.Negeri.Ini

Lockarmy, A and Khuruna, A 1995.Quality Function Deployment: Total Quality Management for new product design. International Journal Quality and Reliability Management, 12: 33-41

Marini, C., Fatchurrohman, N., A., A., \& Suraya, S. 2016. Product Development using QFD, MCDM and the Combination of these Two Methods. IOP Conf. Series: Materials Science and Engineering 114 (2016) 012089. Malaysia: IOP Publishing.

Parasuraman, A., Zeithaml, V. S., \& Berry, L. 1985. A Conceptual Model of Service Quality and Its Implications for Future Research. Journal of Marketing. 49: 41-50.

Purnama, R. .2018.. Jangan ke bengkel mendekati libur lebaran. Retrieved from CNN Indonesia: https://www.cnnindonesia.com/teknologi/20180512082604-389-297593/ jangan-ke-bengkel-mendekati-waktu-libur-lebaran

Sag, F. 2018.. Susul SPIN Chevrolet Captiva discontinue. Retrieved from Cinta Mobil: https://cintamobil.com/pasar-mobil/susul-spin-chevrolet-captiva-benar-benardiscontinue-dari-pasar-indonesia-aid3181

Salim, F. F., \& Dharmayanti, D. 2014. Pengaruh BrandImage dan Perceived Quality Terhadap Kepuasan dan Loyalitas Pelanggan Mobil Toyota di Surabaya. Jurnal Manajemen Pemasaran Petra.2 (1): 1-8.

Sulistriani, E. 2002. Implementasi Quality Function Deployment dalam Pengembangan Produk Lantai Keramik (Studi Kasus pada Classic Tile) [Tesis]. Surabaya: Program Pasca Sarjana Program Studi Teknik Industri, Institut Teknologi Surabaya. 